\title{
Decentralized domestic wastewater systems in developing countries: the case study of Harare (Zimbabwe)
}

\author{
Innocent Chirisa $^{1} \cdot$ Elmond Bandauko $^{1} \cdot$ Abraham Matamanda $^{2} \cdot$ Gladys Mandisvika $^{1}$
}

Received: 29 November 2014/ Accepted: 4 January 2016/Published online: 12 February 2016

(c) The Author(s) 2016. This article is published with open access at Springerlink.com

\begin{abstract}
Until recently there has been little, if any, concern over revamping let alone improving wastewater management system in Zimbabwe's urban areas given the dominance and institutionalised water-borne system. Yet, the current constraints in this system and the immensity of urbanisation in the country begs and compels planners, engineers and systems thinkers to rethink what best can work as a sustainable wastewater system. With particular reference to the ever-expanding Harare metropolitan region, this article provides an evaluative analysis on the potentiality, risks and strategies that can be adopted by Harare and its satellites in addressing the problems of the conventional wastewater management system. The suggested framework of operation is a decentralised domestic wastewater collection and treatment system which however has its own multifarious risks. Using systems dynamics conceptualisation of the potentiality, opportunities, risks and strategies, the paper seeks to model the path and outcomes of this decentralised domestic wastewater collection and treatment system and also suggests a number of policy measures and strategies that the city of Harare and its satellites can adopt.
\end{abstract}

Keywords Waterborne $\cdot$ Sewerage $\cdot$ Risk $\cdot$ Potential · Strategy $\cdot$ Decentralisation $\cdot$ Food production $\cdot$ Source separation

Innocent Chirisa

chirisa.innocent@gmail.com

1 Department of Rural and Urban Planning, University of Zimbabwe, Harare, Zimbabwe

2 Centre for Applied Social Sciences, University of Zimbabwe, Harare, Zimbabwe

\section{Introduction}

Developing countries are burdened with a multiplicity of problems, and wastewater management is increasingly becoming a priority issue. The management of wastewater system in developing countries is exacerbated by accelerating urbanisation, inadequate management and disposal of wastewater and the implementation of sophisticated treatment technologies that are highly centralised (Libralato et al. 2012). The current wastewater management systems are riddled with a plethora of irregularities that calls for a paradigm shift from the current centralised system to the decentralisation in wastewater treatment management. The principal reason for this has been that the provision of centralised systems is not technically, economically or environmentally feasible as De Gisi et al. (2014) notes that the conventional system regards wastewater as 'waste' yet there is potential to make use of the wastewater. Decentralised systems also offer an alternative approach to providing water, wastewater and storm water services to urban areas (Nhapi 2004a, b, c; Libralato et al. 2012). In recent times, the concept of integrating water and wastewater systems through separate collection and treatment of various water and waste streams and recovery of valuable water, nutrients and energy has been proposed. This helps to overcome the limitations of the centralised approach and to move towards more ecologically and economically sound water/wastewater management systems.

Furthermore, innovative decentralised systems are being planned and implemented for new and future urban development either as separate facilities or in combination with a centralised system (Diaper et al. 2007; Brown et al. 2009). Wilsenach (2006: 4) observes that a general critique against classical civil engineering projects is that they have not dealt with transport, drinking water, energy and 
wastewater in an integrated way. These were all designed as linear systems, without consideration of the cyclic character of most natural systems (De Gisi et al. 2014). In urban water management there is a need for a change to improve the sustainability of the systems. This has been a wakeup call from proponents such as Cook et al. (2009) who argue that the conventional centralised systems are not always the most appropriate solution for urban development. Rather, a new approach has to be embraced that should include the integration of social, economic, and environmental aspects with practices such as rainwater management, water conservation, wastewater reuse, rational energy management (incorporating the use of alternative sources), nutrient recovery, and sorting at source (De Gisi et al. 2014; Suriyachan et al. 2012; Brown et al. 2009; Mitchell et al. 2008).

This present paper is an attempted evaluation and analysis of the decentralised wastewater treatment and management systems, putting into picture potentialities, opportunities, risks and strategies. It is a study that emanates from the fact that the conventional centralised wastewater management systems have failed to produce sustainable outcomes in terms of social, economic and environmental concerns. This work reviews some existing technologies applied in decentralised wastewater treatment and disposal in developing countries such as the septic tank, imhoff tank, and soil infiltration device, to name these few (ibid). Technologies that are potentially sound and beneficial for wastewater treatment are also explored. Emphasis is placed on faecal sludge management, which is grossly inadequate, and in some cases totally lacking in rural, peri-urban and some urban areas of developing countries. To demonstrate this, we use documentary and discourse analysis. First, the paper starts by providing an analytical framework, and then proceeds to provide a comparative analysis of the centralised and decentralised systems. The rationale for adoption of decentralised wastewater management system is also explained. Second, the legislative and policy framework for wastewater treatment and management in Zimbabwe is explained, which is then followed by an outline of the current situation in Harare as well as reflections on systems dynamics in the City. Third, the paper ends by a discussion, practical implications, policy options and conclusion.

\section{Decentralised domestic wastewater collection and treatment system: an analytical framework}

This section provides a conceptual reflection of the decentralised wastewater treatment and management systems. The aim of this section is to describe and explain the key features or characteristics of the decentralised wastewater management concept.

Decentralised wastewater system is when raw wastewater is simply treated next to the source (point of generation according to Omenka 2010) through a range of simple technologies. Office of Water United States Environmental Protection Agency (2005: 3) defines decentralised wastewater systems as consisting of a wide range of onsite and cluster treatment systems that process household and commercial sewage. The Rocky Mountain Institute (2004) defines decentralised systems as an alternative to conventional, centralised systems. In addition, the decentralised concept can be explained as an organisational paradigm for wastewater management (De Gisi et al. 2014; Sheehan 2011; Nhapi 2004a, b, c) that entails treating and beneficially reusing wastewater as close to where it is generated as practical, using technologies appropriate to the scale of the facilities (Venhuizen 2003). A decentralised system may consist of individual on-site systems and/or cluster systems, either singly or in combination with more highly collectivised facilities as Libralato et al. (2012) advocates for a combination of a centralised and decentralised so as to maximise on the opportunities of each system. The degree of collectivisation at any stage of the treatment and reuse or dispersal processes will be determined by a variety of local circumstances, including topography, site and soil characteristics, development density, type of development, community desires with regard to land use issues, and sites of potential reuse and/or sites where discharge would be allowable. Some systems in arid regions promote evaporation or wastewater uptake by plants.

However, decentralised wastewater treatment is not without its share of challenges resulting from choice of inappropriate technology, improper siting of infrastructure, in adherence to correct design concepts and lack of proper maintenance (Omenka 2010; Libralato et al. 2012). These bring about negative public health and environmental impacts including groundwater nitrate contamination, eutrophication of surface water bodies and contribution to global warming through the emission of green house gases.

\section{Centralised versus decentralised wastewater management systems: an appraisal}

In developing countries such as Zimbabwe, onsite systems are generally used in high income and low density areas where the collection of infrastructure discourages sewered systems. The wastewater management systems in Latin America are also centralised systems that are contributing to environmental problems (Noyola 2013). As such, the municipal wastewater treatment systems in Latin America 
Table 1 Comparison between centralised and decentralised systems

\begin{tabular}{lll}
\hline Parameter & Centralised system & Decentralised system \\
\hline Collecting system & Large diameters, long distances & Small diameters, short distances \\
Requirements space & Large area in one place & Small areas in many places \\
Operation and maintenance & Full time technical staff requirements & Less demanding, can be monitored remotely \\
Uniformity of water & Many types of water & More uniform water \\
Dilution grade & Less control over the storm water, more dilution & More control over the storm water, more concentrate \\
Risk & Risk on a larger scale & Risk distributed \\
Water transfer & Increase the needs for water transfer & Water is used and reused in the same area \\
Social control & Social control is lost & More social control \\
Ease of expansion & High costs, more complexity to implementation & Low cost, less complexity to implementation \\
Potential to reuse & All water is concentrated in one point & Water can be reused locally \\
\hline
\end{tabular}

Source CODESAB (2011)

are currently unsustainable because they are characterised by high water consumption, especially for transporting wastes out of cities (Suriyachan et al. 2012; Nhapi 2004b). The mixing of industrial waste streams further complicates resource recovery and reuse than if process streams would be kept separate. On this note, De Gisi et al. (2014) castigates centralised system on the basis that they result in high energy and water use as well as increasing the vulnerability of communities to water-borne diseases through leakages of pipes over long distances. Cook et al. (2009) further notes that the centralised collection and treatment of wastewater limits opportunities to harness "waste" as a resource that is otherwise useful if recycled since there is no waste in nature as De Gisi et al. (2014) argues. With, generally, little awareness of environmental consequences, little institutional attention for recovery of resources, and with only degradable organics potentially removed from wastewater effluent or sludge, the remaining resources are either distributed into surface waters or into sludge. As such, wastewater collection and treatment contribute to environmental pollution. Most of the technologies used for centralised treatment of wastewater are expensive (investment and maintenance) and require well-trained staff (Nhapi 2004a, b, c). For these and other reasons, an intermediate or decentralised approach to wastewater management is urgently needed aiming at resource conservation and reducing environmental impacts of current approaches (Cook et al. 2009; Mitchell et al. 2008) (see Table 1).

\section{Rationale for decentralised wastewater treatment and management}

Massoud et al. (2009: 652) argue that centralised wastewater collection and treatment systems are expensive to construct and operate, especially in areas with low population densities and dispersed households. Developing countries lack both the funding to construct centralised facilities and the technical expertise to manage and operate them. The decentralised system is therefore not only a long-term solution for small communities but is more reliable and cost effective. Alternatively, the decentralised approach for wastewater treatment which employs a combination of onsite and/or cluster systems is gaining more attention. Such an approach allows for flexibility in management, and simple as well as complex technologies are available. While there are many impediments and challenges towards wastewater management in developing countries, these can be overcome by suitable planning and policy implementation. Understanding the receiving environment is crucial for technology selection and should be accomplished by conducting a comprehensive site evaluation process. Centralised management of the decentralised wastewater treatment systems is essential to ensure they are inspected and maintained regularly (Nhapi 2004a, b, c). In light of this argument by Nhapi (2004a, b, c), Libralato et al. (2012) echoes the same sentiments and argue that a semi-centralised scheme can be a feasible option to introduce decentralisation in an urban area in a developing country, considering that the planning policies and the regulatory framework do not have many components that facilitate a different kind of management other than the traditional "end-of-the pipe" solutions and with use of conventional technologies in centralised systems.

Bernal and Restrepo (2012: 9-12) have pointed out that environmental pollution, water scarcity, population growth, innovation, and technological developments are drivers that encourage rethinking the current approach to urban water management. In this sense, decentralisation encourages us to think of urban water management in a holistic way, integrating all sectors, drinking water, wastewater, and storm water to get the most benefit out of them, thereby reducing costs, improving environmental management, 
expanding service coverage, and considering social and environmental benefits that are not visible with the current perspective (De Gisi et al. 2014; Werner et al. 2009). Centralised wastewater treatment systems are costly when compared to the decentralised systems. Geisinger and Chartier (2005) notes that sewage collection systems are typically $60-70 \%$ of total project costs for a conventional centralised system hence decentralised systems are economically efficient. According to a study carried out by United Nations (2015) for South-East Asia it emerge that the decentralised system is more economical than the centralised system because treatment facilities for decentralised treatment facilities can be built in an incremental way and requires less initial capital investment than centralised treatment that requires millions of dollars. The above-mentioned should be accompanied by a reform of policies and guidelines that govern urban development plans and water management plans in cities in developing countries. The incorporation of decentralisation as a viable option for wastewater management in urban areas and the regulation of reusing practices such as defining quality criteria are necessary actions to articulate the conceptual framework with the actions that occur in reality. Based on a review of the state of the art and experiences with decentralisation, it can be concluded that the social, financial, and environmental benefits of decentralisation become critical factors when considering this kind of scheme in urban water management plans, mainly in peri-urban areas where wastewater collection and/or treatment is not available. In addition to the benefits, the key issues of each one of the identified economic, social, and environmental categories should be discussed. These include, among others, the cost of collecting and treating wastewater, acceptance and social awareness, and environmental protection, all of which must be considered in implementing decentralisation in urban areas in developing countries (Nhapi 2004a, b, c). According to the context of each case, the level of decentralisation may be a critical issue to achieving sustainability of a wastewater management system. In short, wastewater treatment can be decentralised thereby reducing plumbing and pumping costs, possibility of safe reuse of water for gardening open spaces and can be integrated as part of the landscape.

\section{Global scan on decentralised wastewater treatment systems}

The Decentralised wastewater treatment system was introduced in the Philippines as a way of responding to the problems caused by the conventional system that was in place (UNEP 2012). A new effective system was therefore necessary to prevent further environmental pollution and threats to public health. For the implementation of the decentralized wastewater system in Philippines, the following were required: biogas reactor, settling unit, anaerobic baffled reactor, anaerobic filter and indicator pond (ibid). The same project was also implemented in the Vietnam, where there was training of staff in the Operations and Maintenance of the system. The same impacts of reduced environmental pollution and reduced threats to public health were recorded (UNEP 2012). Gauss (2008) points out that decentralized wastewater treatment systems have been implemented in Central and South America as well as Latin America. The method that was implemented is the constructed wetlands system in Cities such as Masaya (Nicaragua), Lima (Peru), and Pereira (Colombo) and in countries such as Brazil. Recently, the 2009 Melbourne Metropolitan sewerage strategy for Melbourne aims to provide sustainable sewerage services in the city to 2060. The strategy aims to decongest the existing centralised sewerage system for Melbourne through the adoption of decentralised and on-site wastewater systems. The options include secondary and tertiary treatment systems that incorporate re-use of water for non-portable uses, urine separation, black and greywater separation and composting toilets (Brown et al. 2010). The decentralised system has also been used in Georgia, United States where about $40 \%$ of the residents rely on decentralised systems, which prove to be more effective than centralised systems (Sheehan 2011). De Gisi et al. (2014) provides that a lowcost dry sanitation system with or without urine diversion is becoming popular due to a number of factors. The method is based on biological processes that separate urine and faeces resulting in the formation of Terra Preta soils that are eventually used in agriculture. The common technologies currently in use include septic tanks, pit latrines, composting toilets, urine diversion and pour flush. Each strategy and technology comes with its pros and cons and basically fall under two categories namely wet and dry technologies. From the Latin American, Central American and South American Cases, major lessons were drawn about the decentralized wastewater management system. The lessons include the following:

- Low operation and maintenance costs of the system (De Gisi et al. 2014; Bakir 2001).

- Robustness and good contaminant removal (Guo et al. 2014).

- Low environmental impact (Gauss 2008).

Gauss (2008) also argues that decentralized wastewater management systems require an experienced sanitary 
engineer and community participation is key in the selection of preferred technology.

\section{Regional overview on decentralized wastewater systems}

In Southern Africa, countries show different patterns with regards to centralized and decentralized wastewater systems. For example, Kenya uses conventional wastewater treatment systems which are inadequate and non-functional due to higher costs of operation and maintenance (Benard and Omondi 2012). There are also weak institutions mandated with wastewater management. The conventional systems are capital intensive, requiring large sums of shilling which the majority of the local governments do not afford. Windhoek is also one of the Cities in Southern Africa that has shown meaningful progress with regards to the implementation and management of decentralized systems (Moyo 2012). In Malawi and Mozambique De Gisi et al. (2014) maintains that urine diversion technology has been successfully implemented as decentralised wastewater management alternatives.

\section{Local cases on decentralized wastewater systems}

In Zimbabwe, there are cases of decentralised wastewater management system mainly in the rural areas where pit latrines are commonly used. According to Nhapi (2004a, b, c), cases of such a system are in places such as Gweru, Redcliff, Nemanwa and Mupandawana. In Gweru, the decentralized wastewater system started in 1994. In the town of Redcliff, there is evidence of decentralised wastewater treatment and management system as evidenced by the reuse of wastewater for agriculture. Septic tanks are a common wet technology that is used in areas with large plot sizes. The following technologies are used in Redcliff: duckweed pond systems, constructed wetlands and aquaculture. In Mupandawana and Nemanwa, the use and availability of duckweed pond systems provides an opportunity for the implementation of decentralized wastewater treatment and management systems (Nhapi 2004a, b, c). In Zimbabwe, the effective implementation of decentralised wastewater management systems is affected by unavailability of data on basic design of the technologies.
Legislative and policy framework for wastewater management in Zimbabwe

The framework and national strategy for wastewater management is governed by several pieces of legislation that are the responsibility of different Government Ministries and Agencies. In 2007, Statutory Instrument 6 of 2007 of the Environmental Management Act was gazetted as the Environmental Management (Effluent and Solid Waste Disposal) Regulations, 2007. These regulations generally set for the basic framework for wastewater management in Zimbabwe (Thebe and Mangore 2012). The Public Health Act through Statutory Instrument 638 of 1972 gazetted as the Public Health (Effluent) Regulations sets guidelines for wastewater irrigation concerning public health. These guidelines forbid the irrigation of root crops such as potatoes and sets restrictions that are not greatly enforced presently in Zimbabwe (Thebe and Mangore 2012). In terms of Zimbabwean law in the form of Urban Councils Act, Chapter 29.15 and Regional Town and Country Planning Act, Chapter 29.6; all households are compelled to have an acceptable sanitation system before an occupation certificate is issued (Nhapi 2004a, b, c) and this has led to the high sanitation coverage in Zimbabwe urban centres which is estimated at $97 \%$ in the urban areas according to Thebe and Mangore (2012). In a study by Ngwenya (2013) it emerge that there is an average coverage of $83.3 \%$ on average for all councils. The coverage of sewerage network services is at $68.7 \%$, efficiency of collection of sewerage at $27.4 \%$ indicates that large amount of sewerage does not reach treatment plants. However, the challenges in maintaining wastewater infrastructure mean that water is channelled away from the households and industries but could fail to get adequate treatment before re-entering the water courses.

\section{Harare: the current situation}

The City of Harare is Zimbabwe's capital city and its administrative, commercial, and communications centre. Harare is situated at an altitude of $1483 \mathrm{~m}$. The topography of the city is hilly in rocky areas, flatter in the south, and undulating in the north. The population of the City is 2098 199 (Zimstat 2012). Map 1 represents the City of Harare. 
The wastewater treatment and management systems in Harare are currently centralised. Harare has a sewerage system that serves approximately 1.8 million people (about $80 \%$ of the total population) in the formal settlements via flush toilets. However, this system is currently dysfunctional and fails to accommodate the informal settlements where pit latrines and open defecation are widespread (Practical Action 2010). The sewage goes to two large activated sludge plants, Crowborough and Firle, which according to Nhapi (2009) are overloaded. The total design capacity of these plants is $208,000 \mathrm{~m}^{3} /$ day compared to total current inflows of about $300,000 \mathrm{~m}^{3} /$ day, resulting in $44 \%$ overloading (Tsiko and Togarepi 2012). The major shortcoming with the existing treatment system in Harare is that it was originally designed for 250,000 people which is a tenth of the current city's population. Efforts to expand the existing system through a US\$68 million project by City of Harare are likely not to effectively address the wastewater problems currently bedevilling Harare since over 60 million litres of sewage is generated on a daily basis in the southern part of the city (Chideme 2012). Tsoroti (2015) indicates that even if the plant is completed it will only manage to treat $70 \%$ of the wastewater generated. This is having serious implications for downstream water quality. In Epworth, between 1 and $3 \%$ of households had pour-flush toilets; between 23 and $27 \%$ make use of blair latrines while $2-13 \%$ had no toilet facilities.

Large volumes of inadequately treated wastewater are being discharged to the rivers, Marimba and Mukuvisi, which drain to Lakes Chivero and Manyame, the city's major sources of water. Fifty percent $(50 \%)$ of the pollution load discharged into Lake Chivero is attributed to urban wastewater. The city also has two waste stabilisation ponds and an aeration pond; significant quantities of wastewater and sludge are applied to pasture which is a decentralised way of managing waste that just need to be upscaled (Tsoroti 2015). Nhapi et al. (2006) provide very detailed information on wastewater treatment and wastewater impacts on water resources in Harare; they note that a major problem is very high water use (leading to very high wastewater volumes) in relatively wealthy parts of the city (Tsiko and Togarepi 2012). A number of high density areas (Kuwadzana, High field, Dzivaresekwa, Glenview among others) are experiencing unabated sewer bursts for years and remain plagued with pools of raw sewage as council is currently failing to attend to burst sewer pipes citing financial constraints. Such is testimony that the centralised wastewater management and treatment strategies are ineffective and inefficient. The two largest wastewater treatment plants in Harare (Firle and Crowborough) discharge their treated effluents into the Mukuvisi and Marimba rivers, respectively 5 and $8 \mathrm{~km}$ upstream of Lake Chivero (Nhapi 2004a, b, c).

\section{Harare: systems dynamics conceptualisation of the potentiality, opportunities, risks and strategies}

The suitability of the decentralised concept was considered for various land uses. A differentiated (different solutions for different areas) and integrated approach was assumed in which first preference was given to onsite treatment and reuse (Nhapi et al. 2002a, 2002b). The second preference was to treat at a decentralised level what cannot be handled onsite. The third preference was to treat the remainder at a centralised level. Only industrial and low-density residential areas have adequate space for the onsite treatment and reuse of wastewater (Nhapi et al. 2002a, 2002b). One of the major constraints to onsite wastewater management is the difficulty of utilising all the nutrients and water for crop irrigation within the plot boundary. As a result medium $\left(500-1500 \mathrm{~m}^{2}\right)$ and high-density $\left(<500 \mathrm{~m}^{2}\right)$ residential plots are recommended for decentralised systems because they are normally developed as small housing estates and they produce more wastewater than they can utilise onsite.

Decentralised systems would allow housing developments in isolated areas where sewer connection to existing areas would be difficult and expensive (cf. Nhapi 2004a, b, c, 2009; Thebe and Mangore 2012). In such contexts septic tanks may be an option as well as urine diversion where the faeces may be used to increase agriculture production borrowing from the strategy suggested by De Gisi et al. (2014). Considering the variety of sustainable factors, such as social, cultural, environmental, and technical factors, which must be taken into account to implement a wastewater treatment system, the financial aspect is often the most decisive factor in developing countries like Zimbabwe. This is the major reason why decentralised systems are considered as an alternative option. The United Nations (2015) argues in favour of decentralised systems in that treatment facilities can be built in a piece-meal manner and does not require multi-million dollar investments that is usually difficult to raise considering the financial constraints that burden local authorities in developing countries. However, in the majority of countries, there is a lack of suitable institutional arrangements for managing decentralised systems and a lack of a suitable policy framework that encourages a decentralised approach. Without technical assistance and other capacity-building measures, problems of institutional capacity that existed 
under a centralised operation are simply passed on to the new structures (Parkinson and Tayler 2003). For Harare, research and scientific work by responsible institutions is all aimed at improving the centralised wastewater systems, yet the developed world is increasingly shunning these methods.

Similarly, there is limited information on how sustainability applies to the general field of wastewater infrastructure, including both centralised and decentralised treatment approaches. The constraints to decentralised wastewater management systems include, among others, the following:

- government policies and regulations founded on centralised infrastructure,

- market failures, with fragmentation and little information,

- distorted rates of water,

- fragmentation of the water and sanitation agencies,

- civil society based on the conventional,

- minimum investment in research,

- lack of local models that combine technology,

- management, financing and customer acceptance,

- segregation of actors (entrepreneurs, professionals, and academics) in three different areas: supply, storm water and wastewater,

- lack of acceptance public,

- lack of economic evaluations procedures,

- institutional constrains and

- Existing practices.

Harare can adopt various strategies in relation to the decentralised wastewater management concept. From the foregoing it emerges that a number of strategies and technologies can be adopted for wastewater management in a decentralised framework, all effectively treating smaller quantities at or near the source. Septic tanks, pitlatrines and urine diversion are some of the strategies that are gaining popularity as decentralised wastewater management systems (De Gisi et al. 2014). There are also less concentrated wastewater and uses natural treatment methods like algae and duckweed based ponds and constructed wetlands, with harvesting of protein biomass. The other strategies include the use of maturation ponds and anaerobic pre-treatment to allow for stabilisation of organic matter. Algae-based systems are also being used for decentralised systems in Harare. This consists of four treatment lines of small algae-based waste stabilisation ponds scattered in the Mabvuku/Tafara high density area (Nhapi 2004a, b, c). The decentralised or onsite handling of wastewater opens opportunities for simpler methods of wastewater treatment (especially natural methods) and encourages wastewater reuse closer to sources of generation. The adoption of decentralised wastewater management strategy as a sustainable wastewater management in Harare has to consider a number of limitations. First, Harare has an existing extensive infrastructure that has been operational for some years and which represents an enormous capital investment. Therefore, this cannot be phased out overnight and a gradual approach is required. Very few residential areas use communal water and sanitation facilities. Second, land use patterns in Harare exhibit vastly different characteristics so much that it would be irrational to adopt a single solution for all areas. Lifestyles and water use characteristics for low, medium and high-density residential areas are quite different. A differentiated approach is therefore required.

\section{Discussion, policy implications and direction}

The adoption of decentralised wastewater management systems in Harare is still minimal, regardless of the promises of such a concept. The City is used to the conventional centralised systems. A number of factors such as public acceptance, health and cost factors and the availability of alternative water sources rather than technical barriers (Nhapi 2004a, b, c) influence the extent to which the decentralised concept of wastewater treatment and management will be implemented in Harare. Other contributing factors include regulations, convenience and organisations necessary for users if they are to make correct use of wastewater systems. The cost aspect of the decentralised systems is linked to technologies used and the size of population that is to be served by such as system. The technologies are locally available such as duckweed and septic tanks, hence no need for importing such technologies. The availability and cost of alternative water systems (surface, groundwater, rainwater harvesting) is also likely to influence the adoption of decentralised wastewater management in Harare. Water in the Harare metropolitan area is a very serious problem and this may constrain the effective implementation of decentralised systems. Alternative sources of water have to be explored such as rain harvesting. For the effective adoption of decentralised wastewater management strategies, new institutional structures will be required. Cases reviewed from Latin, Central and South America confirms that community engagement is critical factor in the success of the adoption of decentralized wastewater treatment systems. It is therefore important for the City of Harare to engage urban residents in the processes of adopting decentralized wastewater treatment systems. Public awareness is also important so that members of the public are educated on the benefits of implementing such systems in their community. 
Table 2 Issues, potentialities, opportunities, risks and strategies of decentralised wastewater treatment system

\begin{tabular}{lllll}
\hline Issue(s) & Potentialities & Opportunities & Risks & Strategy \\
\hline Financing & $\begin{array}{c}\text { Reduction in } \\
\text { financial cost }\end{array}$ & $\begin{array}{c}\text { Rateable property in } \\
\text { the City }\end{array}$ & $\begin{array}{c}\text { Financial risk in } \\
\text { investments }\end{array}$ & $\begin{array}{c}\text { Tapping of low-cost methods, negotiating with government on } \\
\text { grants for infrastructure development, levying taxes on } \\
\text { households }\end{array}$ \\
$\begin{array}{c}\text { Design } \\
\begin{array}{c}\text { Public } \\
\text { health } \\
\text { design }\end{array}\end{array}$ & $\begin{array}{c}\text { Reduction in } \\
\text { public health } \\
\text { threats }\end{array}$ & $\begin{array}{c}\text { Availability of } \\
\text { engineers } \\
\text { Availability of city } \\
\text { health } \\
\text { departments }\end{array}$ & $\begin{array}{c}\text { Poorly designed } \\
\text { system } \\
\text { Public health risks in of engineers on decentralised wastewater systems, } \\
\text { case of poor designs }\end{array}$ & $\begin{array}{c}\text { Setting standards to ensure public health, review of public health } \\
\text { legislation and policies }\end{array}$ \\
\hline
\end{tabular}

There is also need to review Effluent Standards (Statutory instrument 274 of 2000) and the Public Health Act and other Health regulations to reflect new environmental health standards that are commensurate with the decentralised wastewater treatment and management concept. The decentralised systems should be complemented by water use reduction, pollution, pollution prevention measures, and sources. The decentralised wastewater management strategy is most applicable in high and medium-density residential areas since they have limited space than the low-density areas. Because treatment plants will be scattered around the city, it is best that these be run by local communities, special interest groups (youth, women, churches, nongovernmental organisations), or by private companies. The possibility of financial recovery from systems such as duckweed-based ponds would make them attractive for community management. The other advantage of community management is that it brings environmental management back to the polluters, making it easier for awareness campaigns. Private developers could also be asked to provide small treatment centres for each new housing subdivision and to manage such treatment centres. Private companies could be allowed to manage treatment plants and charge user fees for their services as in the French Model of privatisation of the water sector. The potentialities, opportunities, risks and strategies of the decentralised wastewater treatment system are represented in tabular format (see Table 2). The issues to be considered under decentralised wastewater treatment systems include finance, public health, space, Operation and maintenance and these are linked to the opportunities, potentialities, risks and strategies in the following table or matrix.

\section{Conclusion}

This paper has demonstrated that decentralised wastewater systems are a very important strategy whose adoption can lead to sustainable management of wastewater in the City of Harare. The current socio-economic and environmental challenges currently burdening Harare are drivers that encourage rethinking the current approach to urban water management. In this sense, decentralisation encourages the City of Harare to think of urban water management in a holistic way, integrating all sectors, drinking water, wastewater, and storm water to get the most benefit out of them, thereby reducing costs, improving environmental management, expanding service coverage, and considering social and environmental benefits that are not visible with the current perspective. What is then conspicuous for Harare is a reform of policies and guidelines that govern urban development plans and water management plans. The incorporation of decentralisation as a viable option for wastewater management in urban areas and the regulation of reusing practices such as defining quality criteria are necessary actions to articulate the conceptual framework with the actions that occur in reality.

Based on a review of the state of the art and experiences with decentralisation, it can be concluded that the social, financial, and environmental benefits of decentralisation become critical factors when considering this kind of scheme in developing countries' urban water management plans such as for Harare, mainly in the peri-urban areas, informal settlements and Southern suburbs where wastewater collection and/or treatment is not available. In addition, to the benefits, the key issues of each one of the identified economic, social, and environmental categories should be discussed. These include, among others, the cost of collecting and treating wastewater, acceptance and social awareness, and environmental protection, all of which must be considered in implementing decentralisation in urban areas in developing countries of note in Harare. According to the context of each case, the level of decentralisation may be a critical issue to achieving sustainability of a wastewater management system. Considering the urban form for Harare, a semi-centralised scheme can be a feasible option to introduce decentralisation, considering that the planning policies and the regulatory framework do not have many components that facilitate a different kind of management other than the 
traditional "end-of-the pipe" solutions and with use of conventional technologies in centralised systems.

Open Access This article is distributed under the terms of the Creative Commons Attribution 4.0 International License (http:// creativecommons.org/licenses/by/4.0/), which permits unrestricted use, distribution, and reproduction in any medium, provided you give appropriate credit to the original author(s) and the source, provide a link to the Creative Commons license, and indicate if changes were made.

\section{References}

Bakir HA (2001) Sustainable wastewater management for small communities in Middle East and North Africa. J Environ Manag 61:319-328

Benard O, Omondi G (2012) Wastewater production, treatment and use in Kenya. In: Third regional workshop'safe use of wastewater in agriculture, Johannesburg

Bernal DP, Restrepo I (2012) Key issues for decentralisation in municipal wastewater treatment. In: Paper in the 12th edition of the World Wide Workshop for Young Environmental Scientists (WWW-YES-2012), urban waters: resource or risks? Arcueil, France

Brown R, Farrelly M, Keath N (2009) Practitioner perceptions of social and institutional barriers to advancing a diverse water source approach in Australia. Water Resour Dev 25(1):15-28

Brown V, Jackson DW, Khalife M (2010) 2009 Melbourne metropolitan sewerage strategy: a portfolio of decentralised and on-site concept designs. Water Sci Technol 62(3):510-517

Chideme M (2012) Harare to erect three new sewage treatment plants. http://www.herald.co.zw/harare-to-erect-three-new-sewage-treat ment-plants/. Accessed 24 June 2015

CODESAB (2011) Los Retos: Tratamiento Descentralisado de Aguas Residuales. ForoMetropolitano de Cochabamba del Agua y Saneamiento. Universidad Mayor de San Simón, Bolivia

Cook S, Tjandraatmadja G, Ho A, Sharma A (2009) Definition of decentralised systems in the South East Queensland context. Urban water security research alliance technical report no. 12. http://www.urbanwateralliance.org.au/. Accessed 26 Nov 2014

De Gisi S, Petta L, Wendland C (2014) History and technology of Terra Preta sanitation. Sustainability 6:1328-1345

Diaper C, Sharma A, Tjandraatmadja G (2007) Decentralised water and wastewater systems. In: Newton P (ed) Transitions: pathways towards sustainable urban development in australia, CSIRO Australia Publishing and Springer, The Netherlands

Gauss M (2008) Constructed wetlands: a promising wastewater treatment system for small localities: experiences from Latin America. Water and Sanitation Program (WSP)

Geisinger D, Chartier G (2005) Managed onsite/decentralised wastewater systems as long-term solutions. Clearwaters 35:6-11

Guo X, Liu Z, Chen M, Liu J, Yang M (2014) Decentralized wastewater treatment technologies and management in Chinese villages. Front Environ Sci Eng 8(6):929-936

Libralato G, Ghirardini AV, Avezzu F (2012) To centralize or to decentralize: an overview of the most recent trends in wastewater Treatment management. J Environ Manage 94(1):61-68

Massoud MA, Tarhini A, Nasr JA (2009) Decentralised approaches to wastewater treatment and management: applicability in developing countries. J Environ Manage 90:652-659

Mitchell C, Abeysuriya K, Willetts J (2008) Institutional arrangements for onsite and decentralised systems: needs and opportunities for key players in the field of distributed wastewater management. Paper presented at on site and decentralised sewerage and recycling conference. Australian Water Association in partnership with Environmental Health Australia, Benalla, 12-15 Oct 2008. https://opus.lib.uts.edu.au/bitstream/ 10453/10708/1/2007004570.pdf. Accessed 23 July 2014

Moyo L (2012) Wastewater production, treatment and use in Namibia. In: Third regional workshop'safe use of wastewater in agriculture. Johannesburg

Ngwenya ST (2013) Technical constraints to urban wastewater management in Zimbabwe. MSc Dissertation, Department of Civil Engineering, University of Zimbabwe, Harare. Available at: http://ir.uz.ac.zw/jspui/bitstream/10646/1399/1/UZ_WREM \%20_NGWENYA_FINAL_THESIS_2014.pdf. Accessed 24 Nov 2015 (Unpublished)

Nhapi I (2004a) The potential for the use of duckweed-based pond systems in Zimbabwe. Water SA 30(1):115-120

Nhapi I (2004b) A framework for the decentralised management of wasterwater in Zimbabwe. Phys Chem Earth 29:1265-1273

Nhapi I (2004c) Options for wastewater management in Harare. Taylor and Francis Group, Zimbabwe

Nhapi I (2009) The water situation in Harare, Zimbabwe: a policy and management problem. Water Policy 11(2):221-235

Nhapi I, Hoko Z, Siebel M, Gijzen HJ (2002a) Assessment of major water and nutrient flows in the Chivero catchment area, Zimbabwe. Phys Chem Earth 27(11-12):783-792

Nhapi I, Siebel M, Gijzen HJ (2002b) Options for the decentralised management of wastewater in Harare Zimbabwe, IWA Water and Environmental Management Series, p 955-964

Nhapi I, Siebel MA, Gijzen HJ (2006) A proposal for managing wastewater in Harare, Zimbabwe. Water Environ J 20(2):101-108

Noyola A (2013) Municipal wastewater treatment in Latin-America: a zoom to Mexico with emphasis in GHG Emissions from municipal wastewater treatment. International Development Research Centre. https://www.globalmethane.org/documents/ ww_fs_eng.pdf. Accessed 27 Nov 2014

Office of Water US Environmental Protection Agency (2005) Handbook for managing onsite and clustered (decentralised) wastewater treatment systems: an introduction to management tools and information for implementing EPA's management guidelines. Office of Water US Environmental Protection Agency, Cincinnati

Omenka E (2010) Improvement of decentralised wastewater treatment in Asaba, Nigeria. Master Thesis, Lund University, Water and Environmental Engineering, Department of Chemical Engineering

Parkinson J, Taylor K (2003) Decentralized water management in Periurban areas in low income countries. Environ Urban 15(1):75-89

Practical Action (2010) Low-cost sanitation technology-Zimbabwe. http://practicalaction.org/practicalanswers/product_info.phd?produ cts_id $=408 \&$ atrib $=2$. Accessed 26 July 2015

Rocky Mountain Institute (2004) Valuing decentralised wastewater technologies. A catalog of benefits, costs, and economic analysis techniques. Rocky Mountain Institute, New York

Sheehan KA (2011). Decentralised wastewater treatment in Georgia: Benefits and management need. In: Proceedings of the 2011 Georgia Water Resources Conference held April 11-13, 2011 at the University of Georgia

Suriyachan C, Nitivattananon ATM, Amin N (2012) Potential of decentralized wastewater management for urban development: case of Bangkok. Habit Int 36(1):85-92

Thebe TA, Mangore EN (2012) Wastewater production, treatment and use in Zimbabwe. Department of Civil and Water Engineering, National University of Science and Technology, Bulawayo 
Tsiko RG, Togarepi S (2012) A situational analysis of waste management in Harare, Zimbabwe. J Am Sci 8(4):692-706

Tsoroti S (2015) City aims to double sewage treatment. http://www. hararenews.co.zw/2015/05/city-aims-to-double-sewage-treat ment/. Accessed 24 June 2015

UNEP (2012) Philippines. Decentralized wastewater treatment systems for the San Fernando City Slaughterhouse. A Borda Dewats Project in the Phillipines

United Nations (2015) Market opportunities for decentralized wastewater treatment systems in South-East Asia. In: Regional Policy Workshop on wastewater management and sanitation in South-East Asia, 2 and 3 April 2015, UNCC, Bangkok, Thailand
Venhuizen D (2003) The decentralised concept of "waste" water management. http://www.venhuizen-ww.com/html/dcentral. html. Accessed 26 Nov 2014

Werner A, Panesar A, Rüd SB, Olt CU (2009) Ecological sanitation: principles, technologies and project examples for sustainable wastewater and excreta management. Desalination 248:392-401

Wilsenach JA (2006). Treatment of source separated urine and its effects on wastewater systems. Department of Biotechnology, Delft University of Technology, The Netherlands

Zimstat (2012) Census report. Harare, Government of Zimbabwe 